\title{
Prediction of Portal Vein Thrombosis Following Hepatectomy for Perihilar Cholangiocarcinoma: Efficacy of Postoperative Portal Vein Diameter Ratio and Angle
}

\author{
TSUNEYUKI UCHIDA ${ }^{1}$, YUSUKE YAMAMOTO ${ }^{1}$, TEIICHI SUGIURA ${ }^{1}$, YUKIYASU OKAMURA $^{1}$, \\ TAKAAKI ITO $^{1}$, RYO ASHIDA ${ }^{1}$, KATSUHISA OHGI $^{1}$, TAKESHI ARAMAKI ${ }^{2}$ and KATSUHIKO UESAKA ${ }^{1}$ \\ ${ }^{1}$ Division of Hepato-Biliary-Pancreatic Surgery, Shizuoka Cancer Center, Shizuoka, Japan; \\ ${ }^{2}$ Division of Radiology, Shizuoka Cancer Center, Shizuoka, Japan
}

\begin{abstract}
Background: Portal vein thrombosis (PVT) is a life-threatening complication after hepatectomy. However, the relationship between postoperative PVT and morphometric features of the PV has not been fully elucidated yet. Patients and Methods: A total of 81 patients who underwent hepatectomy for perihilar cholangio-carcinoma (PHCC) were studied. We investigated the diameters and angles of $P V$ using pre- and postoperative computed tomography (CT) reconstructed by SYNAPSE VINCENT ${ }^{\circledR}$. Results: The incidence of PVT after hepatectomy was $11.1 \%$. There were significant differences with respect to the remnant liver $P V$ diameter $(p=0.015)$, the diameter ratio $(p=0.001)$, and the postoperative $P V$ angle $(p=0.001)$ between patients with and without PVT. Multivariate analysis revealed that a postoperative $P V$ angle of less than $90^{\circ}(p=0.008)$ and a diameter ratio of less than $45 \%$ ( $p=0.041$ ) were independent risk factors for PVT. Conclusion: A postoperative PV angle of less than $90^{\circ}$ and diameter ratio of less than $45 \%$ eventually lead to PVT after hepatectomy for PHCC.
\end{abstract}

Because of the recent advancements in perioperative management and surgical techniques, hepatectomy for liver malignant tumor has become a relatively safe surgical procedure $(1,2)$. However, major hepatectomy including the resection of caudate lobe and extrahepatic bile duct and dissection of the regional lymph nodes for perihilar cholangiocarcinoma (PHCC) is associated with a high rate

Correspondence to: Yusuke Yamamoto, MD, Ph.D., Division of Hepato-Biliary-Pancreatic Surgery, Shizuoka Cancer Center, 1007, Shimo-Nagakubo, Sunto-Nagaizumi, Shizuoka, 4118777, Japan. Tel: +81 559895222, Fax: +81 559895551, e-mail: yusu.yamamoto@scchr.jp

Key Words: Perihilar cholangiocarcinoma, portal vein thrombosis, portal vein diameter, portal vein angle. of postoperative morbidity and mortality (3-5). In particular, although portal vein thrombosis (PVT) after hepatectomy is relatively rare, it is one of the most important life-threatening complications after hepatectomy. It potentially induces portal hypertension $(6,7)$, mesenteric congestion, and sepsis (8), which increases postoperative fatal morbidity and mortality.

Previous reports have shown that postoperative PVT after hepatectomy occurs with an incidence of $2.1-9.1 \%(9,10)$. Postoperative PVT is associated with portal flow reduction such as from stenosis, inappropriate positioning, or kinking of the PV $(11,12)$. Recent studies have reported that rightsided hepatectomy, caudate lobectomy, splenectomy, and postoperative bile leakage were independent risk factors associated with PVT after hepatectomy $(9,10)$. After hepatectomy along with caudate lobectomy, especially after right-sided hepatectomy, PV fixation tends to become easily unstable due to the changeable position of the remnant leftsided liver, which can develop stenosis or kinking of the PV (10). We hypothesized that differences in the diameter or the angle of the PV might cause postoperative PVT. As far as we are aware, no study has examined the relationship between the perioperative PV diameter or angle on computed tomographic (CT) images and PVT after hepatectomy.

The aim of this retrospective study was to clarify the risk factors of postoperative PVT, and examine whether narrowing of the PV and sharpening of its angle influence the development of PVT after hepatectomy for PHCC.

\section{Patients and Methods}

Study participants. Patients with PHCC who underwent hepatectomy between January 2009 and December 2016 at the Shizuoka Cancer Center (Shizuoka, Japan), and underwent contrastenhanced CT until postoperative day (POD) 14 were included in this study. The clinical data obtained from these patients were analyzed in this study. The Institutional Review Board of Shizuoka Cancer Center approved this study (approval number J2019-4-2019-1-3). 


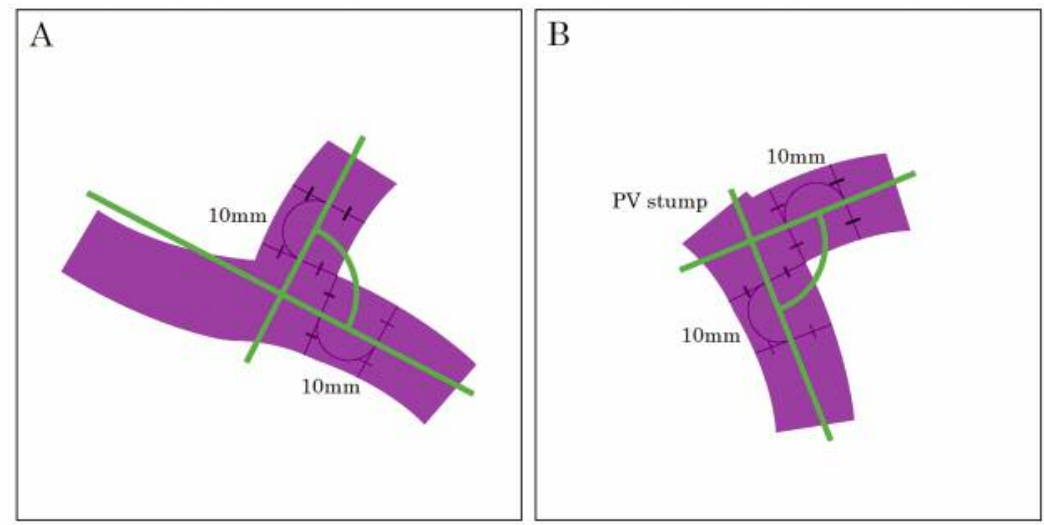

Figure 1. Determination of the angle of the portal vein $(P V)$ in imaging. A: On preoperative images, the center lines of the PVs were used, which were determined by connecting the center points of the cross-section of the bifurcation with the cross-section at 10-mm from the bifurcation. B: On postoperative images, the center lines were determined by connecting the center points of the cross-section of the PV stump with the cross-section at 10-mm from the PV stump.

Procedures of hepatectomy for PHCC. The standard surgical procedure consisted of hepatectomy, total caudate lobectomy, and extrahepatic bile duct resection with regional lymph node dissection $(3,13,14)$. Almost all patients who underwent right-sided hepatectomy or left trisectionectomy underwent PV embolization 23 weeks before hepatectomy $(15,16)$. Combined resection and reconstruction of $\mathrm{PV} /$ hepatic artery was performed when macroscopic tumor invasion was suspected (17). The PV reconstruction following segmental portal resection was performed by end-to-end anastomosis. The posterior wall of the PV was anastomosed by continuous intraluminal suture, and the anterior wall was closed by over-and-over continuous suture. To prevent the remnant liver from rotating and to prevent development of an outflow obstruction, the ligamentum teres was routinely fixed to the original site on the abdominal wall in the case of right-sided hepatectomy. Portal flow at the end of the laparotomy was confirmed using color Doppler ultrasonography.

Postoperative complications were classified according to the grading system of Dindo et al. (18), and grade III or higher complications were considered to be clinically severe.

Diagnosis and management of PVT. Contrast-enhanced CT was postoperatively performed based on the surgeon's judgment. Radiologists reviewed the CT images and cases of PVT. PVT was defined as any thrombosis which had developed in the portal venous system after hepatectomy (8). Patients with PHCC who underwent hepatectomy did not undergo routine postoperative anticoagulation therapy. Patients with PVT underwent surgical thrombectomy or anticoagulation therapy when bleeding disorders were not found. Surgical thrombectomy was generally performed when PVT developed a few days after surgery. Anticoagulation therapy included administering unfractionated heparin to maintain activated partial thromboplastin between $150 \%$ and $200 \%$. Following heparinization, patients received oral dosage of warfarin, targeting a prothrombin time-International Normalized Ratio of between 1.5 and 2.5.

Morphometric analysis of $P V$. CT scanning was carried out using a quadruple-phase, with a 320-detecter CT scanner (Aquilion ONE;
Toshiba Medical Systems, Tochigi, Japan). The scanning parameters were as follows: 1-mm slice thickness, reconstruction of the data at $1 \mathrm{~mm}$ intervals $(0.5 \mathrm{~mm}$ overlap), rotation time of $0.5 \mathrm{~s}$, tube voltage of $135 \mathrm{kV}$ (peak), and tube current of 350-400 mA (19). All of the CT images were evaluated by an independent reviewer who did not have access to the original interpretations or outcomes. The postoperative diameter of PV and the pre- and postoperative angle of the PV was measured on three-dimensional (3D) PV reconstructed models using a SYNAPSE VINCENT ${ }^{\circledR}$ volume analyzer (Fujifilm Medical Co., Tokyo, Japan) $(20,21)$. The diameter of the main PV was defined as the diameter of the portal system directly below the confluence of the splenic and superior mesenteric veins. The remnant liver PV was defined as follows: In cases undergoing right-sided hepatectomy and left hemihepatectomy, the diameter of the right and left PV; in those undergoing left-sided trisectionectomy, the diameter of the posterior extrahepatic branch of the PV. The diameter ratio was defined as the ratio of the remnant liver PV to the main PV diameter. This PV reconstructed model can also achieve precise calculation of the angles of the vessels by rotating 3D images. On preoperative images, the centerlines of the PVs were used, which were determined by connecting the center points of the cross-section of the bifurcation with the cross-section at $10-\mathrm{mm}$ downstream from the bifurcation (Figure 1A). On postoperative images, the center lines were determined by connecting the center points of the crosssection of the upstream of PV anastomosis with the cross-section at $10-\mathrm{mm}$ downstream from the PV anastomosis (Figure 1B). The angle of the PV was defined as follows: in right-sided hepatectomy and left-sided hemihepatectomy, the angle formed between the main PV and the first branch of the PV; in left-sided trisectionectomy, the angle formed between the right PV and the posterior branch of the $\mathrm{PV}$. The viewing plane used for the measurement of the angle was determined by rotating the model in the plane in which two PVs were on the same plane (Figure 2).

Statistical analysis. All continuous variables are expressed as the medians with ranges and were compared using the Mann-Whitney $U$-test. The cut-off values for the continuous variables were determined by plotting receiver operating characteristics curves. 

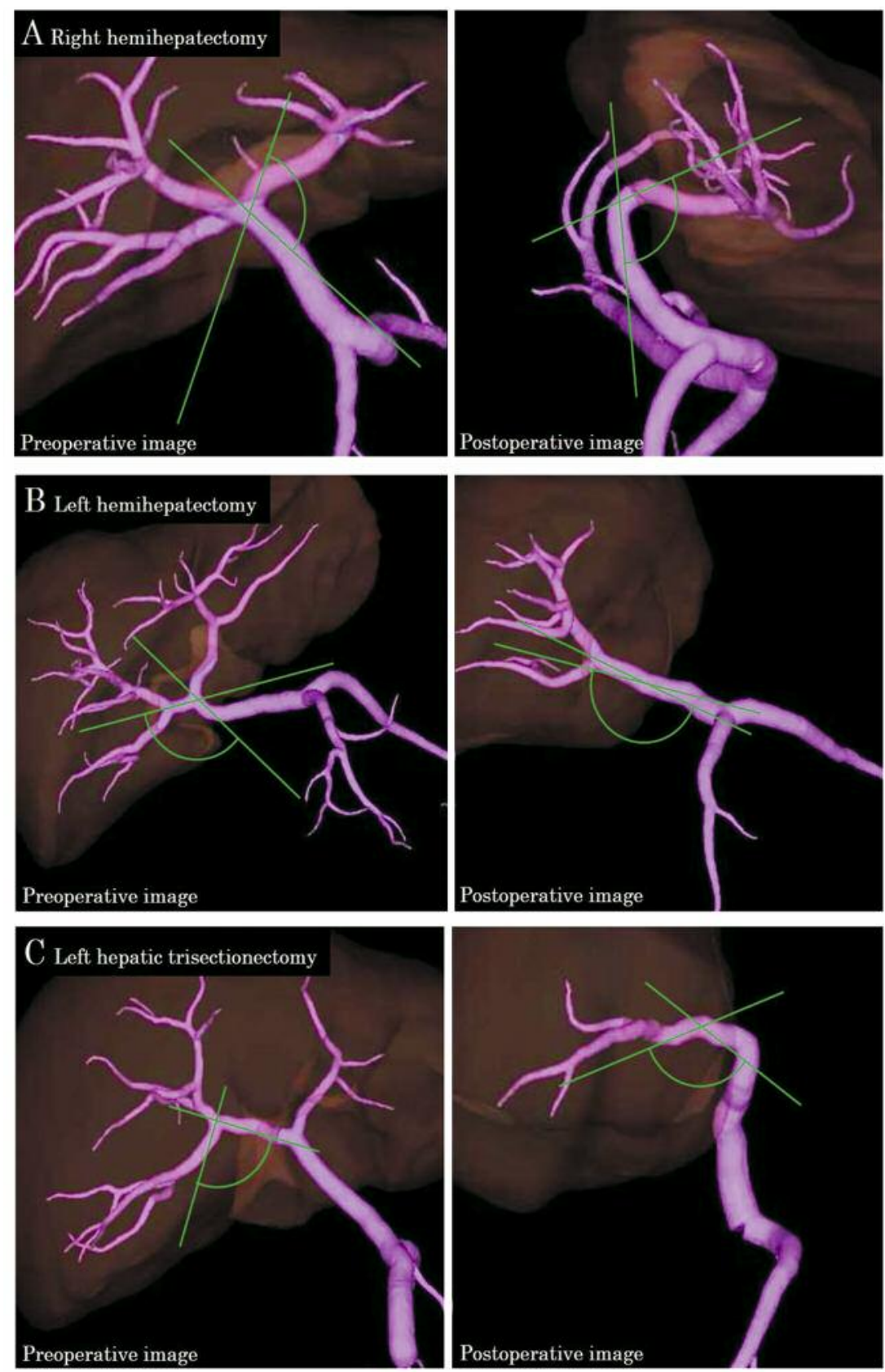

Figure 2. Determination of the angle of the portal vein $(P V)$ in three-dimensional $(3 D)$ reconstructed models. The angle of the PV was defined as the angle formed between the main $P V$ and the first branch of the PV in right-sided hepatectomy $(A)$ and left hemihepatectomy $(B)$. In left hepatic trisectionectomy $(C)$, it was the angle formed between the right $P V$ and the posterior branch of the $P V$.

Comparisons between categorical variables were made using Fisher's exact test. A $p$-value of less than 0.05 was considered statistically significant. Significant prognostic factors evaluated by univariate logistic regression analysis $(p<0.05)$ were included in multivariate logistic regression analysis to determine independent risk factors for PVT. All statistical analyses were performed with EZR (Saitama Medical Center, Jichi Medical University, Saitama,
Japan), which is a graphical user-interface for R (The R Foundation for Statistical Computing, Vienna, Austria) (22).

\section{Results}

Patient demographics. A total of 132 patients underwent hepatectomy for PHCC between January 2009 and December 
2016, of which 51 patients were excluded because they did not undergo contrast-enhanced CT by POD 14. The remaining 81 patients represented the study population, and included 55 men and 26 women with a median age of 72 (range=37-87) years. Preoperative PV embolization was performed in 50 patients $(61.7 \%)$. The surgical procedure was right hemihepatectomy in 31 patients $(38.3 \%)$, right hepatic trisectionectomy in 8 patients $(9.9 \%)$, left hemihepatectomy in 24 patients $(29.6 \%)$, and left hepatic trisectionectomy in 18 patients $(22.2 \%)$. In addition, combined vascular resection with reconstruction was undertaken that involved the PV in 22 patients $(27.2 \%)$. The PV resections included three wedge resections and 19 segmental resections. Reconstruction following portal segmental resection was performed by endto-end anastomosis in 18 or a left renal vein graft interposition in one. PVT was not found intraoperatively in any patient. Severe complications of Clavien-Dindo grade III or more developed in 45 patients $(55.6 \%)$. Four patients $(4.9 \%)$ died due to postoperative complications within 90 days.

Clinical features of patients with PVT. The median time interval from hepatectomy to the postoperative CT analysis was 7 (range=3-14) days. Of the 81 patients, nine developed postoperative PVT (11.1\%) (Table I). The type of hepatectomy included right hemihepatectomy in 4 patients, left hemihepatectomy in 2, and left hepatic trisectionectomy in 3 . Of these nine patients, the Pringle maneuver was carried out in eight and combined PV resection was performed in one using left vein graft. Severe complications were found in six (66.7\%).

Comparison of morphometric variables of $P V$ between patients with and without PVT. Table II shows morphometric variables of PV between patients with PVT and those without. The remnant liver PV diameter was found to be significantly shorter $(p=0.015)$ and the diameter ratio significantly smaller $(p=0.001)$ in patients with PV than those in patients without PVT. The postoperative PV angle was significantly sharper $(p=0.001)$ in patients with PVT than that in patients without PVT.

Univariate and multivariate analyses of risk factors for PVT after hepatectomy for PHCC. The clinical and morphometric variables were assessed as possible risk factors for PVT. In univariate analysis, postoperative PV angle, remnant liver PV diameter, and diameter ratio were significant risk factors for PVT (Table III). Multivariate analysis revealed that a postoperative $\mathrm{PV}$ angle of less than $90^{\circ}$ and a diameter ratio of less than $45 \%$ were independent risk factors for PVT (Table III).

Clinical course of patients with PVT. Details of the nine patients with PVT are shown in Table IV. The location of PVT was the main PV in five patients, superior mesenteric vein in two, and
Table I. Demographics of patients with portal vein thrombosis following hepatectomy for perihilar cholangiocarcinoma $(n=9)$.

\begin{tabular}{lc}
\hline Variable & Value \\
\hline Preoperative & \\
Median age (range), years & $72(37-79)$ \\
Male gender, $\mathrm{n}(\%)$ & $4(44.4 \%)$ \\
Portal vein embolization, $\mathrm{n}(\%)$ & $7(77.8 \%)$ \\
Preoperative biliary drainage, $\mathrm{n}(\%)$ & $8(88.9 \%)$ \\
Type of hepatectomy, $\mathrm{n}(\%)$ & $4(44.4 \%)$ \\
Right hemihepatectomy, $\mathrm{n}(\%)$ & $2(22.2 \%)$ \\
Left hemihepatectomy, $\mathrm{n}(\%)$ & $3(33.3 \%)$ \\
Left hepatic trisectionectomy, $\mathrm{n}(\%)$ & $4(44.4 \%)$ \\
Intraoperative & $1(11.1 \%)$ \\
Pancreatoduodenectomy, $\mathrm{n}(\%)$ & $3(33.3 \%)$ \\
Portal vein resection, $\mathrm{n}(\%)$ & $523(452-851)$ \\
Hepatic artery resection, $\mathrm{n}(\%)$ & $57.2(20.6-140)$ \\
Median operative time (range), min & $1,330(516-4,692)$ \\
Median Pringle time (range), min & $3(33.3 \%)$ \\
Median blood loss (range), ml & \\
Blood transfusion, $\mathrm{n}(\%)$ & \\
\hline
\end{tabular}

PV branch of the segment 2 in one and first jejunum vein in another. Anticoagulation therapy for PVT was performed in seven. Of these, six underwent unfractionated heparin therapy. The remaining patient underwent thrombectomy. The patient with PVT in the PV branch of segment 2 who underwent unfractionated heparin therapy died from other postoperative complications. PVT was resolved in eight patients, including two without undergoing anticoagulation therapy. There were no cases with PVT progression nor any complications in regard to anticoagulation therapy.

\section{Discussion}

The main results of our study are threefold. Firstly, a postoperative PV diameter ratio of less than $45 \%$ and a postoperative PV angle of less than 90 were found to be independent risk factors for PVT after hepatectomy for PHCC. Secondly, right-sided hepatectomy and PV resection, which seemed to influence postoperative PVT, were not deemed independent risk factors for PVT after hepatectomy for PHCC. Lastly, the PVT was resolved in seven out of nine patients but one underwent reoperation and another died because of postoperative complications. These risk factors may be useful for predicting the occurrence of PVT.

A postoperative PV diameter ratio of less than $45 \%$ and postoperative PV angle of less than $90^{\circ}$ were independent risk factors for PVT after hepatectomy for PHCC. Previous studies have reported that hepatectomy with caudate lobectomy may result in kinking and poor positioning of the PV because of its instability $(11,12)$. However, to our 
Table II. Morphological variables of portal vein thrombosis (PVT) after hepatectomy for perihilar cholangiocarcinoma (n=81). Data are median (range).

\begin{tabular}{|c|c|c|c|c|}
\hline Variable & & No PVT (n=72) & $\operatorname{PVT}(\mathrm{n}=9)$ & $p$-Value \\
\hline \multirow[t]{3}{*}{ Diameter, mm } & Postoperative main PV & $13.7(8.1-18.9)$ & $14.8(11.5-19.2)$ & 0.053 \\
\hline & Remnant liver PV & $7.1(3.1-12.8)$ & $5.4(3.7-8.4)$ & 0.015 \\
\hline & Ratio (\%) & $56.2(18.8-95.8)$ & $36.3(19.9-58.1)$ & 0.001 \\
\hline \multirow[t]{2}{*}{ Angle, ${ }^{\circ}$} & Preoperative & $118.8(51.0-167.4)$ & $108.9(54.0-138.6)$ & 0.269 \\
\hline & Postoperative & $116.4(44.6-162.0)$ & $80(44.2-125.0)$ & 0.001 \\
\hline
\end{tabular}

Table III. Univariate and multivariate analysis of risk factors for portal vein thrombosis (PVT) after hepatectomy for perihilar cholangiocarcinoma ( $n=81)$.

\begin{tabular}{|c|c|c|c|c|c|c|}
\hline \multirow[b]{2}{*}{ Variable } & \multirow[b]{2}{*}{ Subgroup } & \multicolumn{3}{|c|}{ Univariate analysis } & \multicolumn{2}{|c|}{ Multivariate analysis } \\
\hline & & No PVT $(n=72)$ & $\operatorname{PVT}(n=9)$ & $p$-Value & OR $(95 \% \mathrm{CI})$ & $p$-Value \\
\hline \multirow[t]{2}{*}{ Age } & $<70$ Years & 21 & 4 & 0.447 & & \\
\hline & $\geq 70$ Years & 51 & 5 & & & \\
\hline \multirow{2}{*}{ Gender } & Male & 51 & 4 & 0.138 & & \\
\hline & Female & 21 & 5 & & & \\
\hline \multirow{2}{*}{ Body mass index } & $<22 \mathrm{~kg} / \mathrm{m}^{2}$ & 40 & 6 & 0.725 & & \\
\hline & $\geq 22 \mathrm{~kg} / \mathrm{m}^{2}$ & 32 & 3 & & & \\
\hline \multirow[t]{2}{*}{ Portal vein embolization } & Absent & 29 & 2 & 0.471 & & \\
\hline & Present & 43 & 7 & & & \\
\hline \multirow[t]{2}{*}{ Preoperative biliary drainage } & Absent & 11 & 1 & $>0.99$ & & \\
\hline & Present & 61 & 8 & & & \\
\hline \multirow[t]{2}{*}{ Type of hepatectomy } & Right-sided & 35 & 4 & $>0.99$ & & \\
\hline & Left-sided & 37 & 5 & & & \\
\hline \multirow{2}{*}{ Pancreatoduodenectomy } & Absent & 50 & 5 & 0.458 & & \\
\hline & Present & 22 & 4 & & & \\
\hline \multirow[t]{2}{*}{ Portal vein resection } & Absent & 51 & 8 & 0.432 & & \\
\hline & Present & 21 & 1 & & & \\
\hline \multirow[t]{2}{*}{ Hepatic artery resection } & Absent & 56 & 6 & 0.431 & & \\
\hline & Present & 16 & 3 & & & \\
\hline \multirow[t]{2}{*}{ Operative time } & $<500 \min$ & 24 & 3 & $>0.99$ & & \\
\hline & $\geq 500 \mathrm{~min}$ & 48 & 6 & & & \\
\hline \multirow{2}{*}{ Pringle time } & $<90 \min$ & 56 & 5 & 0.164 & & \\
\hline & $\geq 90 \mathrm{~min}$ & 11 & 3 & & & \\
\hline \multirow[t]{2}{*}{ Blood loss } & $<1,300 \mathrm{ml}$ & 27 & 4 & 0.726 & & \\
\hline & $\geq 1,300 \mathrm{ml}$ & 45 & 5 & & & \\
\hline \multirow[t]{2}{*}{ Postop. main PV diameter } & $<14 \mathrm{~mm}$ & 42 & 2 & 0.072 & & \\
\hline & $\geq 14 \mathrm{~mm}$ & 30 & 7 & & & \\
\hline \multirow[t]{2}{*}{ Postop. remnant liver PV diameter } & $<5 \mathrm{~mm}$ & 6 & 4 & 0.012 & $1.5(0.7-3.2)$ & 0.268 \\
\hline & $\geq 5 \mathrm{~mm}$ & 66 & 5 & & 1 & \\
\hline \multirow{2}{*}{ Diameter ratio } & $<45 \%$ & 17 & 8 & 0.002 & $12.3(1.1-136)$ & 0.041 \\
\hline & $\geq 45 \%$ & 55 & 1 & & 1 & \\
\hline \multirow{2}{*}{ Preoperative PV angle } & $<90^{\circ}$ & 11 & 4 & 0.056 & & \\
\hline & $\geq 90^{\circ}$ & 61 & 5 & & & \\
\hline \multirow[t]{2}{*}{ Postoperative PV angle } & $<90^{\circ}$ & 13 & 7 & 0.001 & $21.7(2.2-215)$ & 0.008 \\
\hline & $\geq 90^{\circ}$ & 59 & 2 & & 1 & \\
\hline
\end{tabular}

CI: Confidence interval; OR: odds ratio.

knowledge, there has been no report measuring the PV diameter and angle, nor one demonstrating the instability of PV after hepatectomy. Narrowing of PV diameter and sharpening of PV angle may induce venous stasis, which impedes the portal blood flow and can lead to PVT, as is the case in Budd-Chiari syndrome (8). We, therefore, attempted to carry out a morphometric analysis of PVs by measurement of PV diameter and angle on perioperative CT images. In 
Table IV. Clinical course of patients with portal vein thrombosis after hepatectomy for perihilar cholangiocarcinoma $(n=9)$.

\begin{tabular}{cccccccc}
\hline Case & Age (years) & Gender & Type of hepatectomy & PVR & PVT location & Postoperative therapy & Outcome \\
\hline 1 & 37 & Male & R2 & No & MPV & Thrombectomy & Removed \\
2 & 61 & Male & L2 & No & SMV & None & Resolved \\
3 & 73 & Female & L3 & No & MPV & Hesolved \\
4 & 73 & Female & L3 & No & SMV & None & Resolved \\
5 & 60 & Male & L3 & Yes & MPV & Heparin & Resolved \\
6 & 79 & Female & R2 & No & MPV & Hesolved \\
7 & 70 & Female & L2 & No & J1V & Heparin & Resolved \\
8 & 74 & Male & R2 & No & MPV & Resolved \\
9 & 68 & Female & R2 & No & P2 & Unknown \\
\hline
\end{tabular}

PVR: Portal vein resection; R2: right hemihepatectomy; L2: left hemihepatectomy; L3: left hepatic trisectionectomy; MPV: main portal vein; SMV: superior mesenteric vein; J1V: first jejunal vein; P2: portal vein branch of segment 2.

previous reports on PVT after hepatectomy $(9,10)$, major and minor hepatectomies were included. In the present study, all patients underwent major hepatectomy with caudate lobectomy for PHCC. This research was therefore conducted with a limited number of confounding factors. In addition, this is the first report of measurement of PV diameter and angle, which were accurately evaluated by rotating the 3D image. The optimal cut-off value for PV diameter and angle for predicting PVT might be helpful for postoperative management. When a PV diameter ratio of less than $45 \%$ and PV angle of less than $90^{\circ}$ became apparent intraoperatively, it would be necessary to pay greater attention to the increased likelihood of PVT after surgery.

Right-sided hepatectomy and PV resection, which seemed to have an influence on postoperative PVT, were not independent risk factors for PVT after hepatectomy for PHCC. There is a possibility that PVT after right-sided hepatectomy was reduced because we fixed the ligamentum teres to the original site on the abdominal wall in such cases. If the PV is bent after right-sided hepatectomy intraoperatively, it may be better to perform PV resection and reconstruction for straightening the PV. The cause of the relatively high rate of PVT after left-sided hepatectomy may be related to the high rate of left trisectionectomy at our Institution. Left trisectionectomy generally leads to a lower PV diameter ratio, and may often also cause postoperative PVT. Recent reports demonstrated that curative hepatic resection with PV resection, without increasing morbidity, and prognosis of the patients who underwent PV resection showed better outcomes compared with patients with inoperable cancer $(16,23,24)$. Although it is necessary to select applicable patients strictly, surgery combined with PV resection should be performed in order to archive curability.

PVT was resolved in seven out of nine patients, but one patient underwent reoperation and another died because of postoperative complications. Previous studies demonstrated that the rate of complete resolution of PVT after hepatectomy was $80-100 \%$ by anticoagulation therapy, and PVT resolved spontaneously in $60 \%$ of the patients who did not receive anticoagulation therapy after hepatectomy ( 9 , 10). Anticoagulation therapy is commonly used as a treatment for PVT (25). However, the effects of anticoagulation therapy for PVT after hepatectomy are still unclear. A recent retrospective study reported a 5-fold decrease in PVT occurrence following partial liver resection using postoperative administration of low-molecular-weight heparin (26). On the other hand, PV occlusion with extension into the superior mesenteric vein may result in mesenteric congestion, sepsis, and death (8). In this study, mortality resulting from PVT did not occur. However, PVT is a serious complication. Risk factors identified in this study may be useful in predicting the onset of PVT. Patients with these risk factors might undergo postoperative prophylactic anticoagulation therapy.

There are some limitations to the present study. This study was conducted for patients who showed signs of complications because CT was not performed for all cases after hepatectomy for PHCC. Indeed, $11.1 \%$ of the patients developed PVT after hepatectomy for PHCC. The incidence of PVT after hepatectomy for PHCC is higher than that of previous reports $(15,16)$. The bias may be caused by evaluation being performed on a group of patients with a high rate of complications. However, in comparison with previous studies, the number of cases was the largest as a study targeting surgical cases, involving major hepatectomy and caudate lobectomy, and from a viewpoint of careful confounding adjustment, significant research was accomplished.

In conclusion, our results suggest that a postoperative PV angle of less than $90^{\circ}$ and a diameter ratio of less than $45 \%$ are associated with PVT after major hepatectomy with caudate lobectomy for PHCC. Patients with these risk factors who are identified intraoperatively might need to undergo postoperative prophylactic anticoagulation therapy. 


\section{Conflicts of Interest}

The Authors declare no financial or any other type of support for this study

\section{Authors' Contributions}

Designed studies: TU, YY, and KU. Performed assays: TU, YY, and TA. Analyzed data: TU and YY. Wrote article: TU, and YY. Reviewed article: All Authors.

\section{References}

1 Yamamoto Y, Ikoma H, Morimura R, Konishi H, Murayama Y, Komatsu S, Shiozaki A, Kuriu Y, Kubota T, Nakanishi M, Ichikawa D, Fujiwara H, Okamoto K, Sakakura C, Ochiai T and Otsuji E: Changing trends in long-term outcomes after hepatic resection for hepatocellular carcinoma: A 30-year, single-center experience. Anticancer Res 33: 5097-5105, 2013. PMID: 24222155.

2 Yamamoto Y, Ikoma H, Morimura R, Konishi H, Murayama Y, Komatsu S, Shiozaki A, Kuriu Y, Kubota T, Nakanishi M, Ichikawa D, Fujiwara H, Okamoto K, Sakakura C, Ochiai T and Otsuji E: Predictive scoring system assessing the need for intraoperative blood transfusions during hepatectomy for hepatocellular carcinoma. Anticancer Res 34: 313-318, 2014. PMID: 24403480.

3 Nagino M, Ebata T, Yokoyama Y, Igami T, Sugawara G, Takahashi Y and Nimura Y: Evolution of surgical treatment for perihilar cholangiocarcinoma: a single-center 34-year review of 574 consecutive resections. Ann Surg 258: 129-140, 2013. PMID: 23059502. DOI: 10.1097/SLA.0b013e3182708b57

4 Igami T, Nishio H, Ebata T, Yokoyama Y, Sugawara G, Nimura and Nagino M: Surgical treatment of hilar cholangiocarcinoma in the "new era": the Nagoya University experience. J Hepatobiliary Pancreat Sci 17: 449-454, 2010. PMID: 19806294. DOI: 10.1007/s00534-009-0209-0

5 Yamamoto Y, Sugiura T, Okamura Y, Ito T, Ashida R, Aramaki $\mathrm{T}$ and Uesaka K: The pitfalls of left trisectionectomy or central bisectionectomy for biliary cancer: anatomical classification based on the ventral branches of segment VI portal vein relative to the right hepatic vein. J Gastrointest Surg 21: 1453-1462, 2017. PMID: 28667434. DOI: 10.1007/s11605-017-3486-y

6 Amitrano L, Guardascione MA, Brancaccio V, Margaglione M, Manguso F, Iannaccone L, Grandone E and Balzano A: Risk factors and clinical presentation of portal vein thrombosis in patients with liver cirrhosis. J Hepatol 40: 736-741, 2004. PMID: 15094219. DOI: 10.1016/j.jhep.2004.01.001

7 Sogaard KK, Astrup LB, Vilstrup H and Gronbaek H: Portal vein thrombosis: Risk factors, clinical presentation and treatment. BMC Gastroenterol 7: 34, 2007. PMID: 17697371. DOI: $10.1186 / 1471-230 X-7-34$

8 Thomas RM and Ahmad SA: Management of acute postoperative portal venous thrombosis. J Gastrointest Surg 14: 570 557, 2010. PMID: 19582513. DOI: 10.1007/s11605-009-0967-7

9 Yoshiya S, Shirabe K, Nakagawara H, Soejima Y, Yoshizumi T, Ikegami, Yamashita Y, Harimoto N, Nishie A, Yamanaka T and Maehara Y: Portal vein thrombosis after hepatectomy. World J Surg 38: 1491-1497, 2014. PMID: 24407940. DOI: 10.1007/s00268013-2440-8
10 Kuboki S, Shimizu H, Ohtsuka M, Kato A, Yoshitomi H, Furukawa K, Takayashiki T, Takano S, Okamura D, Suzuki D, Sakai N, Kagawa S and Miyazaki M: Incidence, risk factors, and management options for portal vein thrombosis after hepatectomy: A 14-year, single-center experience. Am J Surg 210: 878-885, 2015. PMID: 26307424. DOI: 10.1016/ j.amjsurg.2014.11.021

11 Ganger DR, Klapman JB, McDonald V, Matalon TA, Kaur S, Rosenblate H, Kane R, Saker M and Jensen DM: Transjugular intrahepatic portosystemic shunt (TIPS) for Budd-Chiari syndrome or portal vein thrombosis: Review of indications and problems. Am J Gastroenterol 94: 603-608, 1999. PMID: 10086638. DOI: 10.1111/j.1572-0241.1999.00921.x

12 Dumortier J, Czyglik O, Poncet G, Blanchet MC, Boucaud C, Henry L and Boillot O: Eversion thrombectomy for portal vein thrombosis during liver transplantation. Am J Transplant 2: 934938, 2002. PMID: 12482145.

13 Nimura Y, Hayakawa N, Kamiya J, Kondo S and Shionoya S: Hepatic segmentectomy with caudate lobe resection for bile duct carcinoma of the hepatic hilus. World J Surg 14: 535-543, 1990. PMID: 2166381.

14 Kitagawa Y, Nagino M, Kamiya J, Uesaka K, Sano T, Yamamoto $\mathrm{H}$, Hayakawa $\mathrm{N}$ and Nimura $\mathrm{Y}$ : Lymph node metastasis from hilar cholangiocarcinoma: audit of 110 patients who underwent regional and paraaortic node dissection. Ann Surg 233: 385-392, 2001. PMID: 11224627.

15 Nagino M, Kamiya J, Nishio H, Ebata T, Arai T and Nimura Y: Two hundred forty consecutive portal vein embolizations before extended hepatectomy for biliary cancer: Surgical outcome and long-term follow-up. Ann Surg 243: 364-372, 2006. PMID: 16495702. DOI: 10.1097/01.sla.0000201482.11876.14

16 Watanabe N, Yamamoto Y, Sugiura T, Okamura Y, Ito T, Ashida $\mathrm{R}$, Aramaki $\mathrm{T}$ and Uesaka $\mathrm{K}$ : A predictive scoring system for insufficient liver hypertrophy after preoperative portal vein embolization. Surgery 163: 1014-1019, 2018. PMID: 29501348. DOI: 10.1016/j.surg.2017.11.026

17 Nagino M, Nimura Y, Nishio H, Ebata T, Igami T, Matsushita M, Nishikimi N and Kamei Y: Hepatectomy with simultaneous resection of the portal vein and hepatic artery for advanced perihilar cholangiocarcinoma: an audit of 50 consecutive cases. Ann Surg 252: 115-123, 2010. PMID: 20531001. DOI: 10.1097/SLA.0b013e3181e463a7

18 Dindo D, Demartines N and Clavien PA: Classification of surgical complications: A new proposal with evaluation in a cohort of 6336 patients and results of a survey. Ann Surg 240: 205-213, 2004. PMID: 15273542.

19 Sano S, Yamamoto Y, Sugiura T, Okamura Y, Ito T, Ashida R, Ohgi K, Aramaki T, Nakanuma Y and Uesaka K: The radiological differentiation of hypervascular intrahepatic cholangiocarcinoma from hepatocellular carcinoma with a focus on the CT value on multi-phase enhanced CT. Anticancer Res 38: 5505-5512, 2018. PMID: 30194209. DOI: 10.21873 / anticanres.12884

20 Ohshima S: Volume analyzer SYNAPSE VINCENT for liver analysis. J Hepatobiliary Pancreat Sci 21: 235-238, 2014. PMID: 24520049. DOI: $10.1002 /$ jhbp.81

21 Ogawa C, Minami Y, Morioka Y, Noda A, Arasawa S, Izuta M, Kubo A, Matsunaka T, Tamaki N, Shibatouge M and Kudo M: Virtual sonography for novice sonographers: usefulness of SYNAPSE VINCENT ${ }^{\circledR}$ with pre-check imaging of tumor location. Oncology 87: 50-54, 2014. PMID: 25427733. DOI: $10.1159 / 000368145$ 
22 Kanda Y: Investigation of the freely available easy-to-use software 'EZR' for medical statistics. Bone Marrow Transplant 48: 452-458, 2013. PMID: 23208313. DOI: 10.1038/bmt.2012. 244

23 Ravikumar R, Sabin C, Abu Hilal M, Bramhall S, White S, Wigmore S, Imber CJ, Fusai G and UK Vascular Resection in Pancreatic Cancer Study Group: Portal vein resection in borderline resectable pancreatic cancer: A United Kingdom multicenter study. J Am Coll Surg 218: 401-411, 2014. PMID: 24484730. DOI: $10.1016 /$ j.jamcollsurg.2013.11.017

24 Miyazaki M, Kato A, Ito H, Kimura F, Shimizu H, Ohtsuka M, Yoshidome H, Yoshitomi H, Furukawa K and Nozawa S: Combined vascular resection in operative resection for hilar cholangiocarcinoma: Does it work or not? Surgery 141: 581-588, 2007. PMID: 17462457. DOI: 10.1016/j.surg.2006.09.016
25 Condat B, Pessione F, Hillaire S, Denninger MH, Guillin MC, Poliquin M, Hadengue A, Erlinger S and Valla D: Current outcome of portal vein thrombosis in adults: Risk and benefit of anticoagulant therapy. Gastroenterology 120: 490-497, 2001. PMID: 11159889.

26 Yamashita Y, Bekki Y, Imai D, Ikegami T, Yoshizumi T, Ikeda T, Kawanaka H, Nishie A, Shirabe K and Maehara Y: Efficacy of postoperative anticoagulation therapy with enoxaparin for portal vein thrombosis after hepatic resection in patients with liver cancer. Thromb Res 134: 826-831, 2014. PMID: 25156238. DOI: $10.1016 /$ j.thromres.2014.07.038

Received May 21, 2019 Revised July 9, 2019 Accepted July 12, 2019 